\title{
Dampak Pemberian Tugas Berbantuan Video Terhadap Perkembangan Motorik Halus Anak Usia Dini
}

\section{Ni Luh Made Dian Andriani 1*, I Wayan Wiarta ${ }^{2}$, Ni Nyoman Ganing 3}

1,2 Prodi Pendidikan Anak Usia Dini, Universitas Pendidikan Ganesha, Singaraja, Indonesia

\section{ART I CLE IN F O}

\section{Article history:}

Received July 23, 2021

Revised July 28, 2021

Accepted October 20, 2021

Available online December 25, 2021

Kata Kunci:

Perkembangan Motorik Halus,

Media Audio Visual, Pandemi

Covid-19

\section{Keywords:}

Fine Motor Development, AudioVisual Media, Covid-19 Pandemic

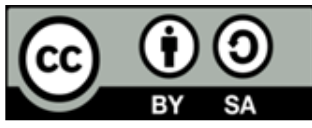

This is an open access article under the CC BY-SA license.

Copyright (C) 2021 by Author. Published by Universitas Pendidikan Ganesha.

\begin{abstract}
A B S T R A K
Wabah Covid-19 menyebabkan pelaksanaan kegiatan belajar mengajar harus dilaksanakan secara daring. Namun, sekolah menerapkan system semi daring sehingga pada saat anak sekolah, pendidik dapat mengevaluasi dan mensinkronkan hasil karya pada saat full daring dan semi daring untuk mengetahui perkembangan motorik halus anak. Penelitian ini bertujuan untuk menganalisis penngaruh pemberian tugas berbatuan video di masa pandemic terhadap perkembangan motorik halus anak usia dini kelompok $\mathrm{B}$. Rancangan eksperimen non-equivalent post-test only control group designPopulasi berdasarkan kelas B terdiri dari 3 kelas yakni B1, B2, B3 sehingga total populasi yaitu 77 orang anak. Sampel dipilih dengan metode random sampling. Data diperoleh berdasarkan metode non-tes dengan instrumen penelitian melalui lembar tes kuesioner. Metode analisis yang digunakan yaitu analisis statistik deskriptif, dengan melakukan uji hipotesis statistic dengan uji t. Berdasarkan hasil analisis diketahui bahwa terdapat perbedaan yang signifikan perkembangan motorik halus anak usia dini yang dibelajarkan menggunakan media audio visual dan kelompok anak yang dibelajarkan dengan pembelajaran konvensional di TK. Jadi, pemberian tugas di masa pandemi menggunakan media audio visual berpengaruh signifikan terhadap perkembangan motorik halus anak usia dini kelompok B.
\end{abstract}

\section{A B S T R A C T}

The Covid-19 outbreak has forced teaching and learning activities out online. However, the school implements a semi-online system so that when children are in school, educators can evaluate and synchronize their work when they are entirely online and semi-online to determine the child's fine motor development. This study aims to analyze the effect of giving video-based assignments during a pandemic on the fine motor development of early childhood group B. Non-equivalent post-test only control group design The population-based on class B consisted of 3 classes, namely B1, B2, B3 so that the total population was 77 children. The sample was selected by the random sampling method. The data was obtained through a questionnaire test sheet on the non-test method with the research instrument. The analytical method used is a descriptive statistical analysis by testing statistical hypotheses with a t-test. Based on the analysis results, it is known that there are significant differences in the fine motor development of early childhood children who are taught using audio-visual media and groups of children who are taught using conventional learning in kindergarten. So, giving assignments during the pandemic using audio-visual media had a significant effect on the fine motor development of early childhood group $B$.

\section{PENDAHULUAN}

Pendidikan merupakan usaha sadar dan terencana dalam mewujudkan pembelajaran anak secara aktif dan kreatif sehingga dapat mengembangkan potensi diri anak (Indy et al., 2019; Supriadi, 2016). Pendidikan yang baik dilaksanakan dengan mengembangkan potensi dan kemampuan anak sesuai dengan usianya baik melalui motorik, daya berpikir dan juga kemampuan bersosialisasi. Maka dari itu stimulasi pendidikan yang harus didapatkan oleh anak usia dini harus kompleks, sehingga perkembangan potensi anak berkembang secara baik. Pendidikan tidak terlepas dari proses pembelajaran,pembelajaran yang diberikan harus sesuai dengan kebutuhan dan tingkat perkembangan anak (Fauziddin \& Mufarizuddin, 2018; Tiara, 2020; Botutihe et al., 2021). Perkembangan dan pembelajaran yang dilaksanakan kepada anak usia dini sepatutnya dilaksanakan dengan mengkombinasikan pembelajaran dan permainan untuk 
meningkatkan ransangan aspek perkembangan usianya. Namun saat ini proses pembelajaran sedang mengalami perubahan yang sangat besar, akibat adanya pandemic Covid-19. Berbagai upaya pencegahan tersebarnya COVID-19 agar tidak semakin parah kemudian menyebabkan masyarakat perlu membatasi kegiatan aktivitas harian dan sosialnya. Makadari itu, pemerintah Indonesia mengeluarkan aturan mengenai adanya pembatasan kegiatan termasuk dalam bidang pendidikan (Handayani et al., 2020; Harahap et al., 2021; Satrianingrum \& Prasetyo, 2020). Kebijakan yang dikeluarakan oleh pemerintah berkaitan dengan pembatasan kegiatan yang melibatkan orang banyak seperti seminar, study banding, workshop dan pembelajaran yang harusnya tatap muka harus diubah menjadi pembelajaran online dibatalkan (Mishra et al., 2020; Oyedotun, 2020; Patricia, 2020; Sahu, 2020). Pembelajaran dalam jaringan (daring/e-learning), yaitu system belajar dengan memanfaatkan jaringan internet yang dilakukan antara pendidik dan peserta didik dalam waktu pembelajaran dan materi yang (Agustin et al., 2020; Fauziddin \& Mufarizuddin, 2018; Harahap et al., 2021). Pembelajaran dilaksanakan dengan memanfaatkan media online berupa whatsApp, facebook, zoom meeting, google meet dengan membuat perencanaan pelaksanaannya ataupun membuat perencanaan kegiatan yang dapat diambil oleh orang tua ke lembaga dengan memperhatikan protokol kesehatan (Chang et al., 2020). Peranan tenaga pendidik sangatlah penting dalam memecahkan permasalahan yang terjadi sehingga para pendidik dan pemerintah harus mampu bekerjasama dalam menerapkan kebijakan pendidikan selama COVID-19 ini terjadi.Peran guru dalam pembelajaran memegang posisi yang sangat penting, strategis dan bahkan menjadi kunci untuk mencapai pembelajaran yang bermutu dan efektif.

Namun, para pendidik merasa kesulitan dalam mengembangkan pembelajarannya. Sebagian besar kegiatan belajar mengajar dilaksanakan melalui Penutupan sekolah menciptakan kesulitan yang harus diatasi untuk melanjutkan kegiatan pendidikan dan proses pedagogis umum dan dalam data baru ini penggunaan dan pengembangan alat komunikasi elektronik tidak dapat dihindari. Berbagai permasalahan terjadi karena dunia pendidikan kesulitan untuk mengembangkan dan menstimulasi potensi anak secara langsung yang disebabkan oleh kegiatan belajar mengajar hanya dilaksanakan secara virtual (Pudyastuti \& Budiningsih, 2021; Shaleh \& Anhusadar, 2021). Penyelenggaraan melalui daring perlu memperhatikan berbagai aspek pendidikan secara ekstra namun dirasa kurang efektif karena terbatasnya waktu, jangkauan, tenaga pendidikan, dan beberapa hambatan lainnya. (Foti, 2020; Muhdi et al., 2020; Naciri et al., 2020; Simamora, 2020). Tantangan dan kesulitan pembelajaran jarak jauh dengan sistem daring yang terjadi lebih dirasakan oleh para guru PAUD dan orang tua siswa, karena dalam proses pembelajaran siswa PAUD dilaksanakan melalui adanya berbagai macam alat peraga, pendampingan, dan pengawasan secara langsung oleh guru dan orang tua untuk menimbulkan rasa semangat anak usia dini saat melaksanakan pembelajaran. Kekurangan yang dihadapi saat pelaksanaan pembelajaran siswa PAUD adalah tidak adanya interaksi langsung sehingga saat pembelajaran online anak-anak tidak bisa menyerap materi yang disampaikan oleh guru dengan baik, anak-anak tidak dapat berinteraksi dan bermain bersama temantemannya sehingga akan mudah mengalami stress karena jenuh (Jayawardana et al., 2020; Nurkolis \& Muhdi, 2020; Purwanto et al., 2020). Kejenuhan yang dialami oleh para siswa PAUD tersebut akan berdampak pada kehidupan sehari-harinya. Kecenderungan akan rasa bosan yang dirasakan oleh anakanak menimbulkan sikap anak yang lebih cenderung senang bermain sehingga orang tua mengalami kesulitan untuk mengajak anak belajar dan menjadi beban tersendiri (Kurniati et al., 2020; Wijayanti \& Fauziah, 2020). Kondisi pembelajaran seperti ini akan berdampak terhadap perkembangan anak. Salah satu perkembangan anak usia dini adalah perkembangan motorik halus.

Kemampuan motorik halus adalah gerakan yang mengunakan otot-otot halus atau sebagai anggota tubuh tertentu yang di pengaruhi oleh kesempatan untuk belajar dan berlatih (Maghfirah, 2019; Rici \& Zulminiati, 2019; Yuningsih \& Hasanah, 2018). Perkembangan motoric halus berdapak terhadap kesaipan anak dalam menulis, melatih koordinasi antara mata dana tangan (Sidabutar \& Siahaan, 2019). Perkembangan motorik halus anak akan berkembang pesat saat berusia 5 tahun seperti koordinasi tangan, dan jari semua bergerak dibawah perintah mata (Fitria et al., 2018). Kemampuan motorik halus anak perlu dikembangkan melalui kegiatan yang menyenangkan (Utomo et al., 2018). Kondisi saat ini motoric masih belum dikatakan optimal hal ini didukung oleh analisis awal yang dilakukan yang menyatakan bahwa Perkembangan motorik halus Anak Kelompok B di TK Shanti Kumara III Sempidi pada masa pembelajaran via daring sejak awal tahun ajaran 2020/2021 ditemukan hambatan pada anak dalam melakukan kegiatan pembelajaran yakni mewarnai ditandai dengan anak belum bisa mewarnai dengan rapi, anak masih mewarnai tanpa melihat garis gambar atau kata lain masih ada goresan krayon yang melewati garis gambar, anak belum mampu mewarnai sesuai dengan arahan.Sistem belajar daring pada TK Shanti Kumara III Sempidi pada awal tahun pelajaran adalah full daring, anak-anak belajar di rumah dengan mengerjakan tugas yang sudah pendidik bagikan pada orang tua murid setiap satu minggu sekali, dan pendidik memberikan tugas beserta video cara mengerjakan melalui WhatsApp Group setiap harinya. Mulai pertengahan Oktober 2020, sudah menggunakan sistem semi daring, anak-anak sekolah tatap muka dengan 
memperhatikan protokol kesehatan dan hanya dengan 10 anak per hari.Pada saat anak sekolah, pendidik dapat mengevaluasi dan mensinkronkan hasil karya pada saat full daring dan semi daring untuk mengetahui perkembangan motorik halus anak.Setiap individu memiliki bakat dan minat yang berbeda-beda, namun pendidik perlu menstimulasi anak dalam motorik halus anak melalui kegiatan mewarnai agar anak bisa mengerjakan tugasnya dengan baik dan rapi.

Pembelajaran yang dilaksanakan secara daring menawarkan pemberian tugas yang praktis dan fleksibel dalam pelaksanaannya sehingga bagi orang tua maupun guru dapat melaksanakan laporan tugas dimanapun dan kapanpun secara terjangkau dan cepat disertai dengan adanya penilaian yang dapat diunggah dengan cepat.Tugas yang diberikan oleh pihak sekolah di masa pandemi ini dilaksanakan guna memenuhi kebutuhan pendidikan sesuai dengan kurikulum yang berlaku, namun sulit bagi pendidik untuk menstimulasi aspek perkembangan anak, karena tidak dapat bertemu langsung dengan siswa. Apabila metode pemeberian tugas ini dapat dilakukan dengan tepat dan terarah maka akan mampu meningkatkan ketrampilan berpikir, dari yang sederhana hingga kemampuan yang lebih kompleks (Arsy, 2019;Anugrahana, 2020). Pada saat masa pandemi ini pendidik perlu memanfaat teknologi komunikasi dalam mengajar, seperti mengirimkan video tutorial mewarnai dengan baik pada WhatsApp Group dengan bahasa yang mudah dipahami oleh anak dan orang tua dirumah.Berdasarkan permasalahan tersebut, penelitian ini bertujuan untuk mengetahui pengaruh yang signifikan pemberian tugas di masa pandemi menggunakan media audio visual terhadap perkembangan motorik halus anak usia dini kelompok B TK Shanti Kumara III Sempidi untuk dapat menjadi acuan dalam menerapkan pembelajaran di dalam pandemi covid-19 agar tetap berjalannya sistem pembelajaran di PAUD guna meningkatkan perkembangan motorik halus anak usia dini di kelompok B.

\section{METODE}

Penelitian ini menggunakan rancangan eksperimen non-equivalent post-test only control group design. Setelah didapatnya satu kelompok kelas kontrol dan eksperimen, maka akan diberikan perlakuan pada masing-masing kelompok. Pada kelompok eksperimen pembelajaran dilakukan dengan pemberian tugas pada anak usia dini di masa pandemi menggunakan media audio visual dalam mengembangkan motorik halus anak. Sedangkan kelompok kontrol yang menggunakan model konvensional pembelajaran dilakukan dengan pemberian tugas pada anak usia dini kelompok B.Dalam desain ini terdapat dua kelompok yang masing-masing dipilih secararandom.Penelitian dilaksanakan pada anak usia dini kelompok B yang terdiri dari 3 kelas yakni B1, B2, B3 TK Shanti Kumara III Sempidi dengan total populasi yang terdiri atas 77 orang anak. Sampel dipilih dengan metode random sampling dengan cara pengundian pada tiga kelas. Penelitian ini memiliki dua variabel yakni pemberian tugas dengan media video tutorial (sebagai variabel dependen), dan perkembangan motorik halus anak usia dini kelompok B (sebagai variabel independent) dengan data yang diperoleh berdasarkan metode non-tes yakni observasi, penyusunan rencana kegiatan, pelaksanaan tes akhir dan diakhiri dengan pengolahan data untuk mengetahui efektivitas pembeian tugas pada anak usia dini di masa pandemi dalam rangka mengembangkan motorik halus anak. Instrumen Penelitian, yang digunakan dalam penelitian adalah lembar tes kuesioner untuk mengukur keterampilan motorik halus. Untuk memudahkan menyusun rubrik penilaian analitik diperlukan kisi-kisi dalammengembangkan motorik halus berbantuan metode pemberian tugas pada anak usia dini di jabarakan pada Table 1. Dalam penelitian ini, validitas instrument yang digunakan adalah validitas isi (content validity) dengan menggunakan guru dan dosen PG PAUD sebagai ahli atau judges Validitas ini dimaksudkan untuk mengetahui seberapa instrumen tersebut telah mencerminkan isi yang dikehendaki. Oleh karena itu, untuk memenuhi validitas isi tersebut, instrumen berupa kuesioner ini disusun berdasarkan terampil tidaknya siswa dalam kegiatan mewarnai. Teknik analisis data yang digunakan adalah statistik deskriptif untuk mendeskripsikan data perilaku belajar yang menggunakan model pembelajaran Project-Based Outdoor Learning Activity menggunakan media Audio Visual dan perilaku belajar yang menggunakan model pembelajaran konvensional. Selanjutnya data akan diuji dengan menggunakan uji hipotesis statistik untuk menarik kesimpulan mengenai berpengaruhnya media audio visual yang digunakan.

Tabel 1. Kisi-Kisi Kuesioner Penelitian Dalam Mengembangkan Motorik Halus Pada Anak Usia Dini Berbantuan Metode Pemberian Tugas.

\begin{tabular}{cll}
\hline No & Variabel & Butir Soal \\
\hline 1. & Mewarnai sesuai arahan yang diberikan oleh guru & $1,2,3$ \\
2. & Menunjukkan kreativitasnya pada kegiatan mewarnai & $4,5,6$ \\
\hline
\end{tabular}




\section{HASIL DAN PEMBAHASAN}

Hasil

Kelompok eksperimen pada penelitian ini yaitu kelompok B2 TK Shanti Kumara III dengan metode pemberian tugas dengan media audio visual, yakni video tutorial mewarnai dalam pembelajaran daring melaluli WhatsApp sebanyak 6 kali pertemuan, kemudian diberikan Posttest untuk memperoleh hasil perilaku belajar anak. Kemudian dilanjutkan dengan kelompok kontrol, yaitu kelompok B1 TK Shanti Kumara III dengan model pembelajaran konvensional di sekolah sebanyak 6 kali kali pertemuan, kemudian diberikan Posttest untuk memperoleh hasil perilaku belajar anak. Berikut adalah sajian data dari masingmasing kelompok tersebut.Berdasarkan penelitian yang dilaksanakan ditemukan bahwa hasil data perilaku belajar anak kelompok eksperimen adalah nilai rata-rata dari Kelompok eksperimenB2 TK Shanti Kumara III dengan metode pemberian tugas dengan media audio visual, yakni video tutorial mewarnai dalam pembelajaran daring melaluli WhatsApp sebanyak 6 kali pertemuan, kemudian diberikan Posttest untuk memperoleh hasil perilaku belajar anak adalah 94.80.Berdasarkan penelitian yang dilaksanakan ditemukan bahwa hasil data frekuensi perilaku belajar anak kelompok eksperimen dijabarakan pada Tabel 2. Hasil distribusi frekuensi terdapat 29 anak dengan nilai tertinggi yang diperoleh 92,67 dan skor terendah 70,83. Dari sebaran data tersebut diperoleh mean (rata-rata) sebesar 82,60, standar deviasi perilaku belajar anak pada kelas kontrol adalah 5,68 dan variansnya 32,32. Hasil perhitungan, dengan membandingkan rata-rata persentase yang diperoleh yaitu 82,60=83, kemudian dengan kriteria PAP Skala 5 (Lima) angka rata-rata 82,60 berada pada kategori Baik 80-89. Berdasarkan data perilaku belajar anak kelompok B2 dan kelompok B1 TK Shanti Kumara III Sempidi bahwa nilai rata-rata anak kelompok B2 dengan menggunakan model pembelajaran pemberian tugas menggunakan video tutorial mewarnai $=91,18$ lebih tinggi dibandingkan nilai rata-rata anak kelompok B1 dengan menggunakan pembelajaran konvensional = 82,60, sehingga dapat disimpulkan pemberian tugas dengan media video tutorial mewarnai lebih baik dari pembelajaran konvensional karena video lebih menarik, ibaratkan seperti anak menonton kartun.

Tabel 2. Distribusi Frekuensi Hasil Data Prilaku Belajar Anak Kelompok Eksperimen

\begin{tabular}{cccc}
\hline No. & Nilai & Frekuensi(f) & Fx \\
\hline 1 & 79,17 & 1 & 79,17 \\
2 & 83,33 & 2 & 166,66 \\
3 & 87,50 & 7 & 612,50 \\
4 & 91,67 & 12 & 1100,04 \\
5 & 95,83 & 5 & 479,15 \\
6 & 100 & 3 & 300 \\
\hline & & $\mathbf{3 0}$ & $\mathbf{2 7 3 7 , 5 2}$ \\
\hline
\end{tabular}

Kelompok kontrol yang terdiri dari kelompok B1 TK Shanti Kumara III dengan model pembelajaran konvensional di sekolah sebanyak 6 kali kali pertemuan.Setelah mengikuti pembelajaran secara konvensional sebanyak 6 kali, di akhir eksperimen anak diberikan Posttest untuk memperoleh data perilaku belajar anak. Berdasarkan hasil penelitian, diperoleh nilai rata-rata dari Kelompok kontrol B1 TK Shanti Kumara III dengan metode pembelajaran konvensional di sekolah sebanyak 6 kali kali pertemuan.Setelah mengikuti pembelajaran secara konvensional sebanyak 6 kali, di akhir eksperimen anak diberikan Posttest untuk memperoleh data perilaku belajar anak dengan hasil nilai rata-rata sebesar 88,60. Berdasarkan penelitian yang dilaksanakan ditemukan bahwa hasil data frekuensi perilaku belajar anak kelompok eksperimen dijabarakan pada Tabel 3.Data perilaku belajar anak kelompok eksperimen pada tabel distribusi frekuensi terdapat 29 anak dengan nilai tertinggi yang diperoleh 92,67 dan skor terendah 70,83. Dari sebaran data tersebut diperoleh mean (rata-rata) sebesar 82,60, standar deviasi perilaku belajar anak pada kelas kontrol adalah 5,68 dan variansnya 32,32. Selanjutnya mean (rata-rata) dari perilaku belajar anak dapat ditentukan dengan mengkonversikan rata-rata persen perilaku belajar dengan menggunakan kriteria PAP skala 5 (lima), dan diperoleh hasil sebesar 0,826\%. Berdasarkan hasil perhitungan tersebut, dengan membandingkan rata-rata persentase yang diperoleh yaitu 82,60 $=83$, kemudian dengan kriteria PAP Skala 5 (Lima) angka rata-rata 82,60 berada pada kategori Baik 80-89. Berdasarkan data perilaku belajar anak kelompok B2 dan kelompok B1 TK Shanti Kumara III Sempidi bahwa nilai rata-rata anak kelompok B2 dengan menggunakan model pembelajaran pemberian tugas menggunakan video tutorial mewarnai $=91,18$ lebih tinggi dibandingkan nilai rata-rata anak kelompok B1 dengan menggunakan pembelajaran konvensional $=82,60$, sehingga dapat disimpulkan pemberian tugas dengan media video tutorial mewarnai lebih baik dari pembelajaran konvensional karena video lebih menarik, ibaratkan seperti anak menonton kartun. 
Tabel 3. Distribusi Frekuensi Hasil Data Perilaku Belajar Anak Kelompok Kontrol

\begin{tabular}{cccc}
\hline No. & Nilai & Frekuensi (f) & Fx \\
\hline 1 & 70,83 & 2 & 141,66 \\
2 & 75,00 & 8 & 633,36 \\
3 & 79,17 & 7 & 583,1 \\
4 & 83,30 & 7 & 612,5 \\
5 & 87,50 & 2 & 150 \\
6 & 91,67 & 3 & 275,01 \\
\hline & JUMLAH & $\mathbf{2 9}$ & $\mathbf{2 3 9 5 , 6 3}$ \\
\hline
\end{tabular}

Analysis selanjutnya adalah uji prayarat yaitu uji normalitas dan homogenitas. Hasil uji normalitas diperoleh skor $\mathrm{X}_{\text {hitung }}=7,81<\mathrm{X}_{\text {tabel }}=11,07$ ini berarti data hasil penelitian berdistribusi normal. Sedangkan, hasil uji homogenitas diperoleh $F_{\text {hitung }}=1,29$ dan $F_{\text {tabel }}=1,76$. Hal ini berarti $F_{\text {hitung }} \leq F_{\text {tabel, }}$ sehingga data memiliki varians yang homogen. Berdasarkan hasil uji prasyarat, disimpulkan bahwa data kedua kelompok sampel berdistribusi normal dan memiliki varians yang homogen. Dengan demikian, uji hipotesis menggunakan uji-t dapat dilakukan. Hipotesis yang diuji dalam penelitian ini yaitu tidak terdapat perbedaan yang signifikan perilaku belajar antara kelompok anak yang dibelajarkan melalui pemberian tugas mewarnai dengan media video tutorial mewarnai dengan kelompok anak yang dibelajarkan melalui pemberian tugas pembelajaran konvensional kelompok BTK Shanti Kumara III Sempidi Tahun Ajaran 2020/2021. Hasil uji prasyarat dalam penelitian ini diperoleh kedua kelompok sampel berdistribusi normal dan memiliki varians yang homogen. Analisis statistik yang digunakan untuk menguji hipotesis penelitian ini adalah uji-t. Hasil analisis uji-t diperoleh nilai $t_{\text {hitung }} \geq t_{\text {tabel }}$ yakni $6,21 \geq 2,000$, hal ini berarti terdapat perbedaan signifikan terhadap pemberian tugas dimasa pandemi terhadap perkembangan motorik halus anak usia dini kelompok BTK Shanti Kumara III Sempidi.

\section{Pembahasan}

Pembelajaran via daring selama pandemi yang dilaksanakan pada TK Shanti Kumara III Sempidi dilaksanakan dengan mengkombinasikan pembelajaran dan permainan untuk meningkatkan ransangan aspek perkembangan anak usia dini. Hal ini dilaksanakan guna meningkatkan perhatian siswa agar tidak merasa jenuh akan pembelajaran tidak langsung. Tugas yang diberikan oleh pihak sekolah di masa pandemi ini dilaksanakan guna memenuhi kebutuhan pendidikan sesuai dengan kurikulum yang berlaku sehinggda dapat mengarahkan kemampuan berpikir siswa dan kreativitas yang dimiliki. TK Shanti Kumara III Sempidi memiliki hambatan saat pelaksanaan kegiatan pembelajaran daring dengan kurangnya kemampuan anak dalam mewarnai secara rapi dan tidak sesuai arahan serta anak masih mewarnai tanpa melihat garis gambar atau kata lain masih ada goresan krayon yang melewati garis gambar. Dalam penelitian ini pemberian tugas berbantuan video berpengaruh positif terhadap kemampuan motoric halus anak.Hal ini karena Video menjadikan anak sebagai pembelajar yang pasif maupun aktif dengan melihat vidio, mendengarkan arahan tutor (guru), serta mengaplikasikannya secara langsung.Dengan menggunakan media video tutorial dalam pemberian tugas untuk mengasah motorik halus anak merupakan suatu kelebihan karena anak dapat mengulangi video tersebut secara berulang-ulang ketika belum paham. Selain itu, video akan membantu daya ingat anak menjadi meningkat, karena ada berbagai sumber yang bisa digunakan sebagai bahan referensi untuk anak belajar dirumah seperti youtube.Peningkatan kreativitas anak pada siklus pertama dan kedua di dalam kegiatan menggambar bebas melalui penggunaan metode pemberian tugas untuk meningkatkan kreativitas anak di kelompok B (Tirtayati et al., 2014). Serta hasil penelitian yang menyatakan meningkatkan perkembangan bahasa anak di kelompok B TK Budhi Luhur Sudaji melalui kegiatan permainan puzzle huruf (Suryastini et al., 2014). Jika dikaitkan dengan hasil penelitian yang telah dilaksanakan sebelumnya, peranan guru saat memberikan tugas melalui media audio visual sangatlah penting untuk dilaksanakan karena dapat meningkatkan kreativitas anak dalam kegiatan pembelajaran bagi anak usia dini agar tak merasa kejenuhan namun dapat mengkombinasikan permainan dan pembelajaran secara menarik dan sesuai dengan arahan kurikulum yang berlaku.Pembelajaran menggunakan model pembelajaran video tutorial dalam pemberian tugas dimasa pandemi merupakan salah satu upaya pada saat ini.Yang berdapak terhadap kemamampuan motoric halus.

Kemampuan motorik halus adalah gerakan yang mengunakan otot-otot halus atau sebagai anggota tubuh tertentu yang di pengaruhi oleh kesempatan untuk belajar dan berlatih (Maghfirah, 2019; Rici \& Zulminiati, 2019; Yuningsih \& Hasanah, 2018). Perkembangan motoric halus berdapak terhadap kesaipan anak dalam menulis, melatih koordinasi antara mata dana tangan (Sidabutar \& Siahaan, 2019). Perkembangan motorik halus anak akan berkembang pesat saat berusia 5 tahun seperti koordinasi tangan, dan jari semua bergerak dibawah perintah mata (Fitria et al., 2018). Kemampuan motorik halus anak perlu 
dikembangkan melalui kegiatan yang menyenangkan (Utomo et al., 2018). Penelitian ini memiliki keunggulan yakni memudahkan guru untuk mengajar, kemampuan anak meningkat dalam pemecahan masalah dan meningkatkan motivasi belajar anak. Dengan menggunakan media video tutorial dalam pemberian tugas untuk mengasah motorik halus anak merupakan suatu kelebihan karena anak dapat mengulangi video tersebut secara berulang-ulang ketika belum paham. Selain itu, video tutorial ini akan membantu daya ingat anak menjadi meningkat, karena ada berbagai sumber yang bisa digunakan sebagai bahan referensi untuk anak belajar dirumah seperti youtube. Sehingga pembelajaran yang diterapkan pada TK Shanti Kumara III Sempidi melalui media audio visual sangatlah penting untuk dilaksanakan karena dapat meningkatkan kreativitas anak dalam kegiatan pembelajaran bagi anak usia dini agar tak merasa kejenuhan namun dapat mengkombinasikan permainan dan pembelajaran secara menarik dan sesuai dengan arahan kurikulum yang berlaku. Hasil penelitian ini berkontribusi sebagai bahan masukan bagi guru untuk memilih model pembelajaran yang bervariasi dalam mengajar dimasa pandemi ini.Salah satunya adalah dengan menerapkan model pembelajaran video tutorial dalam pemberian tugas mewarnai pada anak, tujuannya untuk memudahkan dalam mengasah perkembangan motorik alus anak di dalam pembelajaran daring saat ini. Implikasi teoritis dalam penelitian ini yaitu pemilihan model pembelajaran yang tepat dapat berpengaruh terhadap perilaku belajar anak, dan Penelitian ini membuktikan bahwa model pembelajaran dalam pemberian tugas dengan media video tutorial mewarnai untuk mengasah motorik alus anak usia dini baik diterapkan dalam proses pembelajaran sebagai upaya mengoptimalkan perilaku perkembanga belajar anak.

\section{SIMPULAN}

Terdapat pengaruh pemberian tugas di masa pandemi terhadap perkembangan motorik halus anak usia dini ditemukan adanya perbedaan yang signifikan. Pemberian tugas di masa pandemi dilaksanakan melalui penerapan media audio visual untuk perkembangan motorik halus anak usia dini dengan menggunakan Video Tutorial dalam pemberian tugas mewarnai. Video tutorial menjadikan anak sebagai pembelajar yang pasif maupun aktif dengan melihat video, mendengarkan arahan tutor (guru), serta mengaplikasikannya secara langsung.

\section{DAFTAR RUJUKAN}

Agustin, M., Puspita, R. D., Nurinten, D., \& Nafiqoh, H. (2020). Tipikal Kendala Guru PAUD dalam Mengajar pada Masa Pandemi Covid 19 dan Implikasinya. Jurnal Obsesi: Jurnal Pendidikan Anak Usia Dini, 5(1), 334-345.

Anugrahana, A. (2020). Hambatan, Solusi dan Harapan : Pembelajaran Daring Selama Masa Pandemi Covid19 Oleh Guru Sekolah Dasar. Scholaria: Jurnal Pendidikan Dan Kebudayaan, 10(3), 282-289. https://ejournal.uksw.edu/scholaria/article/view/4033.

Arsy, S. (2019). Meningkatkan Kreativitas Anak Usia Dini Melalui Metode Pemberian Tugas Di Naafi'ah Jakarta Baru Kotabumi. UIN Raden Intan Lampung.

Botutihe, S. N., Smith, M. Bin, Kasan, I. A., \& Hilala, R. (2021). Strategi Pembelajaran Physical Distancing Guru PAUD dalam Menghadapi Pandemi Covid19. Jurnal Obsesi: Jurnal Pendidikan Anak Usia Dini, 5(2), 1536-1543.

Chang, T. Y., Hong, G., Paganelli, C., Phantumvanit, P., Chang, W. J., Shieh, Y. S., \& Hsu, M. L. (2020). Innovation of dental education during COVID-19 pandemic. Journal of Dental Sciences, 155. https://doi.org/10.1016/j.jds.2020.07.011.

Fauziddin, M., \& Mufarizuddin, M. (2018). Useful of Clap Hand Games for Optimalize Cogtivite Aspects in Early Childhood Education. Jurnal Obsesi: Jurnal Pendidikan Anak Usia Dini, 2(2), 162. https://doi.org/10.31004/obsesi.v2i2.76.

Fitria, D., Wulan, D. S. A., \& Yarshal, D. (2018). Pengaruh Kegiatan Handicraft Terhadap Motorik Halus Anak Tk Kelompok B Di Tk Karunia Kecamatan Tuntungan. Jurnal Tarbiyah, 25(2). https://doi.org/10.30829/tar.v25i2.369.

Foti, P. (2020). Research in distance learning in greek kindergarten schools during the pandemic of COVID19: Possibilities, dilemmas, limitations. European Journal of Open Education and E-Learning Studies, 5(1), 19-40. https://doi.org/10.5281/zenodo.3839063.

Handayani, D., Hadi, D. R., Isbaniah, F., Burhan, E., \& Agustin, H. (2020). Corona virus disease 2019. Jurnal Respirologi Indonesia, 40(2), 119-129. https://doi.org/10.36497/jri.v40i2.101.

Harahap, S. A., Dimyati, D., \& Purwanta, E. (2021). Problematika Pembelajaran Daring dan Luring Anak Usia Dini bagi Guru dan Orang tua di Masa Pandemi Covid 19. Jurnal Obsesi : Jurnal Pendidikan Anak Usia Dini, 5(2), 1825-1836. https://doi.org/10.31004/obsesi.v5i2.1013. 
Indy, R., Waani, F. J., \& Kandowangko, N. (2019). Peran Pendidikan Dalam Proses Perubahan Sosial Di Desa Tumaluntung Kecamatan Kauditan Kabupaten Minahasa Utara. HOLISTIK, Journal Of Social and Culture, 12(4), 1-21. https://ejournal.unsrat.ac.id/index.php/holistik/article/view/25466.

Jayawardana, H. B. ., Zahro, I., \& Pertiwi, E. P. (2020). Identifikasi Kesulitan Guru Paud Di Masa Pandemi Covid-19 Dan Solusinya. PAUDIA : Jurnal Penelitian Dalam Bidang Pendidikan Anak Usia Dini, 9(2), 40-50. https://doi.org/10.26877/paudia.v9i2.6647.

Kurniati, E., Nur Alfaeni, D. K., \& Andriani, F. (2020). Analisis Peran Orang Tua dalam Mendampingi Anak di Masa Pandemi Covid-19. Jurnal Obsesi: Jurnal Pendidikan Anak Usia Dini, 5(1), 241. https://doi.org/10.31004/obsesi.v5i1.541.

Maghfirah, S. (2019). Pemanfaatan Barang Bekas dalam Meningkatkan Kemampuan Motorik Halus Anak. Atfālunā: Journal of Islamic Early Childhood Education, 2(1), 48-52. https://doi.org/10.32505/atfaluna.v2i1.938.

Mishra, D. L., Gupta, D. T., \& Shree, D. A. (2020). Online Teaching-Learning in Higher Education during Lockdown Period of COVID-19 Pandemic. International Journal of Educational Research Open, 100012. https://doi.org/10.1016/j.ijedro.2020.100012.

Muhdi, Nurkolis, \& Yuliejantiningsih, Y. (2020). The Implementation of Online Learning in Early Childhood Education During the Covid-19 Pandemic. JPUD - Jurnal Pendidikan Usia Dini, 14(2), 247-261. https://doi.org/10.21009/jpud.142.04.

Naciri, A., Baba, M. A., Achbani, A., \& Kharbach, A. (2020). Mobile Learning in Higher Education: Unavoidable $\begin{array}{llll}\text { Alternative } \quad \text { during } & \text { COVID-19. } & \text { ep20016. }\end{array}$ https://doi.org/10.29333/aquademia/8227.

Nurkolis, N., \& Muhdi, M. (2020). Keefektivan Kebijakan E-Learning berbasis Sosial Media pada PAUD di Masa Pandemi Covid-19. Jurnal Obsesi: Jurnal Pendidikan Anak Usia Dini, 5(1), 212-228.

Oyedotun, T. D. (2020). Sudden change of pedagogy in education driven by COVID-19: Perspectives and evaluation from a developing country. Research in Globalization, 2(June), 100029. https://doi.org/10.1016/j.resglo.2020.100029.

Patricia, A. (2020). College Students' Use and Acceptance of Emergency Online Learning Due to COVID-19. International Journal of Educational Research Open, 100011. https://doi.org/10.1016/j.ijedro.2020.100011.

Pudyastuti, A. T., \& Budiningsih, C. A. (2021). Efektivitas Pembelajaran E-Learning pada Guru PAUD Selama Pandemic Covid-19. Jurnal Obsesi : Jurnal Pendidikan Anak Usia Dini, 5(2), 1667-1675. https://doi.org/10.31004/obsesi.v5i2.873.

Purwanto, A., Pramono, R., Asbari, M., Santoso, P. B., Wijayanti, L. M., Choi, C. H., \& Putri, R. S. (2020). Studi Eksploratif Dampak Pandemi COVID-19 Terhadap Proses Pembelajaran Online di Sekolah Dasar. EduPsyCouns: Journal of Education, Psychology and Counseling, 2(1), 1-12.

Rici, R., \& Zulminiati. (2019). Efektivitas Mozaik Bahan Alam (Sisik Ikan) Terhadap Motorik Halus Anak. Jurnal Pendidikan Dan Pembelajara Anak Usia Dini, 6(2), 109-113. https://doi.org/10.21107/pgpaudtrunojoyo.v6i2.6152.

Sahu, P. (2020). Closure of Universities Due to Coronavirus Disease 2019 (COVID-19): Impact on Education and Mental Health of Students and Academic Staff. Cureus, 2019(4), 4-9. https://doi.org/10.7759/cureus.7541

Satrianingrum, A. P., \& Prasetyo, I. (2020). Persepsi Guru Dampak Pandemi Covid-19 terhadap Pelaksanaan Pembelajaran Daring di PAUD. Jurnal Obsesi: Jurnal Pendidikan Anak Usia Dini, 5(1), 633. https://doi.org/10.31004/obsesi.v5i1.574.

Shaleh, M., \& Anhusadar, L. (2021). Kesiapan Lembaga PAUD dalam Pembelajaran Tatap Muka pada New Normal. Jurnal Obsesi: Jurnal Pendidikan Anak Usia Dini, 5(2), 2158-2167. https://doi.org/10.31004/obsesi.v5i2.1139.

Sidabutar, R. R., \& Siahaan, H. (2019). Peningkatan Motorik Halus Anak Usia Dini melalui Pemanfaatan Media Daun dalam Kegiatan Pembelajaran. Atfālunā: Journal of Islamic Early Childhood Education, 2(1), 39-47. https://doi.org/10.32505/atfaluna.v2i1.930.

Simamora, R. M. (2020). The Challenges of Online Learning during the COVID-19 Pandemic: An Essay Analysis of Performing Arts Education Students. Studies in Learning and Teaching, 1(2), 86-103. https://doi.org/10.46627/silet.v1i2.38.

Supriadi, H. (2016). Peranan Pendidikan Dalam Pengembangan Diri Terhadap Tantangan Era Globalisasi. Jurnal Ilmiah Prodi Manajemen Universitas Pamulang, 3(2), 92-119. https://doi.org/10.32493/jk.v3i2.y2016.p\%25p.

Suryastini, L. A., Wirya, I. N., \& Ujianti, P. R. (2014). Penerapan Metode Pemberian Tugas Berbantuan Media Puzzle Huruf Untuk Meningkatkan Perkembangan Bahasa Pada Anak TK. E-Journal PG-PAUD Universitas Pendidikan Ganesha, 2(1). 
Tiara, D. \& P. (2020). Pentingnya Mengukur Kesiapan Guru Sebagai Dasar Pembelajaran Daring. Jurnal Golden Age, 04(2), 362-368.

Tirtayati, N. P. E., Suarni, N. K., Magta, M., \& (2004:186), M. (2014). Penerapan Metode Pemberian Tugas Untuk Meningkatkan Kreativitas Anak Melalui Kegiatan Menggambar Bebas. Jurnal Pendidikan Anak Usia Dini Undiksha, 2(1), 4.

Utomo, I. A., Ramli, M., \& Furaidah. (2018). Penerapan Strategi Bermain melalui Media Busy Book untuk Meningkatkan Fisik Motorik Halus Anak Usia Dini. Jurnal Pendidikan: Teori, Penelitian, Dan Pengembangan, 3(12), 1594-1598. https://doi.org/10.17977/jptpp.v3i12.12553.

Wijayanti, R. M., \& Fauziah, P. Y. (2020). Perspektif dan Peran Orangtua dalam Program PJJ Masa Pandemi Covid-19 di PAUD. Jurnal Obsesi: Jurnal Pendidikan Anak Usia Dini, 5(2), 1304-1312. https://doi.org/10.31004/obsesi.v5i2.768.

Yuningsih, A., \& Hasanah, U. (2018). Penggunaan Playdogh Dalam Mengembangkan Motorik Halus. AlAthfaal: Jurnal Ilmiah Pendidikan Anak Usia Dini, 1(1), 117-128. https://doi.org/10.24042/ajipaud.v1i1.3408. 